\title{
Assessing the Internal Audit Practice and Its Role in Protecting and Effective Utilization of Public Resources: Evidence from Sector Bureaus in SNNPRS
}

\author{
Ayneshet Agegnew Alemu Kanbiro Orkaido Deyganto* \\ Lecturers, School of Postgraduate Studies, Pharma College Hawassa Campus, Ethiopia
}

\begin{abstract}
Internal auditing is an independent objective assurance and consulting activity designed to add value and improve an organization's operation and it helps an organization accomplish its objectives by bringing a systematic, disciplined approach to evaluate and improve the effectiveness of risk management, control, and governance processes. To this end, the objective of this study is to assess the internal audit practice and its role in effective use of public resource with reference to public bureau sin SNNPRS. In conducting this study, the researchers have employed a descriptive design with qualitative research approach due to qualitative nature of data required to prepare the report of this study. The primary data were collected from respondents in selected public bureaus of southern Ethiopia. Then, descriptive statistics analysis has been done through SPSS version 20.0. So, the result of the study showed that the internal audit practice plays a significant role in protection and effective utilization of public resources. Besides, it found out that lack of expertise, lack of management support, lack of opportunity for professional development, lack of information technology facilities and lack of positive and supportive attitude toward internal controls, restricted access to necessary audit evidence, and wrong perception towards the audit function were main challenges of auditors work performance in one hand and limits effective utilization of public resources in SNNPRS. Based on the findings of the study, the researcher forwarded possible recommendations for the public bureaus in SNNPRS, Ethiopia to improve the function of internal audit in effective and efficient utilization of public resource.
\end{abstract}

Keywords: Internal audit practice, Public Resources utilization, SNNPRS, Ethiopia

DOI: $10.7176 /$ RJFA/10-15-06

Publication date: August $31^{\text {st }} 2019$

\section{Introduction}

\subsection{Background and Problematizing the issue}

Public sector bureaus are part of the public body which is partly or wholly financed by government budget and concerned with providing basic government services to the whole society (MO FED, 2004). Internal Auditing is very essential in any organization particularly in public organizations because it gives attention on the evaluation of various controls, examining deviation from applicable standards and any instance or act of irregularity, inefficiency and ineffectiveness with the motive of taking corrective action. Hence, the internal auditors have a significant contribution to control any noncompliance activity in line with the established policies, plans, procedures, laws and regulations, set by the government if they use some techniques to recognize misstatements in clients accounting system and report the Misstatements) which has a significant impact on the organization's operations. Therefore, this research is very essential for the public sector offices in SNNPRS to be aware how to effectively utilize public resources.

Internal auditors assist both management, boards of directors and audit committees by examining, evaluating and reporting on the adequacy and effectiveness use of public resources by recommending improvements when necessary. Hence, Study by (Mihret and Yismaw, 2007) suggested that Internal audit unit in Ethiopian in public Sectors needs to enhance the technical proficiency of the internal audit unit, and minimize staff turnover because internal audit's lack of authority on budgets reduces its control of resource acquisition and utilization, and improvement in the areas of audit planning, documentation of audit work, audit communications and follow-up of recommendations.

Hence studying internal audit become common agenda of study by researchers outside Ethiopia in general and in Ethiopia in particular. For example, researchers such as (Enofe et.al, 2013; Taiwo et al, 2014; Vani, 2010; Kirima, 2016; Dawuda, 2010; Morteza, 2014) outside ethiopia and research results of (Hawa, 2016; Belay, 2007; Amina, 2016; Shewamene, 2014; Samuel, 2008; and Tesema, 2018) in ethipia found that internal auditing practice contributes to effective use of public resources in one hand promote public governance. But as per internet browes, no study has been carried out on same topic in SNNPRS and conducting this study can be used as the corner stone for assessing internal audit practice and enables the bureaus and encourages future researchers by being as literature review. 


\subsection{Objective of the study}

To this end, the general objective of this study is assessing the internal audit practice and its contributions to effective utilization of public resources with to bureaus in SNNPRS, Ethiopia. Besides, the research has the following Specific objectives:

a) To examine the role of internal audit in effective utilization of public resources in SNNPRS

b) To assess the challenges internal audit practice in public resources in of bureaus in SNNPRS.

\subsection{Justification of the study}

Internal audit unit is responsible for evaluating and contributing to the improvement of good governance, improved operation of the organization, risk management and control process using a systematic and disciplined approach of any organization. Therefore, this research enables the SNNPRS government public sector bureaus, specifically the managements, the higher responsible body and audit committee of selected public sectors to be aware of the importance internal auditor role and gives insight how they use the internal auditor service most efficiently. Besides, this research was used as a beginning for those who are interested to conduct a detailed and comprehensive study regarding the role of internal auditor in safeguarding public resource in SNNPRS public sector bureaus.

\section{Materials and Methods}

\subsection{Description of Study Area}

The current study was undertaken in the Southern Nations, Nationalities and People's Regional State in government organization with internal audit department. Southern Nations, Nationalities, and Peoples' Region (SNNPR). It is one of the nine ethnic divisions of Ethiopia. Its capital is Hawassa.

\subsection{Research Design and Approach}

This study was used descriptive research design in order to the assess the role of internal auditing in effective utilization of public resources. Researcher used qualitative data that collected through questionnaire. Hence, the study used qualitative research approach due to qualitative nature of the topic under study.

\subsection{Population, Sample size and Sampling Techniques}

Population of the study: The target population of the study is $129(3 * 43)$ employees in one internal auditor position, one accountants and top management in the selected bureaus of SNNPRS.

Sampling Techniques: This study used a simple random sampling method in selecting respondents who provide sufficient information that helpful in preparing report of this study.

Sample size determination: Sample size of study selected by using formula calculated below. Sample size was determined by using formula of (Yamane, 1967).

$$
\begin{gathered}
\frac{\boldsymbol{N}}{\mathbf{1}+(\boldsymbol{e}) 2 * \mathrm{~N}} \\
\text { Where: } \mathrm{n}=\text { sample size } \\
\mathrm{N}=\text { population size } \\
\mathrm{e}=\text { Precision level or sampling error }=0.07
\end{gathered}
$$

Hence, the researcher applied the formula as $n=\frac{129}{\mathbf{1 + ( 0 . 0 7 ) 2 * 1 2 9}}=98$. Hence, the total sample size of the study is 98 respondents.

\subsection{Data type, source, collection and analyze methods}

In this study the researcher used both primary and secondary data sources. The primary data sources were respondents from selected public organizations. It was collected by distributing questionnaire. Secondary data were obtained from documents, reports, journals, proceedings, bulletins, internet, periodicals, various books and other relevant materials through review. Then, descriptive statistics has been used by the student researcher to analyze the data.

\subsection{Ethical considerations}

The following ethical considerations have been given attention by the student researcher while conducting this research. These are: vvoluntary participation has assured, no harm to participants, Cconfidentiality of the data, not deceiving the subjects and Privacy of participants has respected.

\section{Results of this study}

In order to conduct data analysis, the researcher distributed 98 questionnaires has been distributed to the respondents. Out of the total 98 questionnaires distributed, sixty (60) questionnaires were correctly filled and returned. This implies that the response rate of the research was fifty eight point eight percent $(58.8 \%)$ which 
indicates more than half of respondents were participated in the process of data collection.

\subsection{Reliability Analysis}

Table 1 Reliability Statistics

Cronbach's Alpha 0.626

Cronbach's Alpha Based on Standardized Items

$\mathrm{N}$ of Items 10

Source: questionnaire (2019)

As it can see from the table above, the value for Cronbach's Alpha $(\alpha)$ was 0.626 for items which close to 0.70 which accepted as minimum standard

\subsection{The role of internal audit in effective utilization of public resource}

The researcher has used three Likert scale to assess the whether internal audit role in public sector is effective resource utilization. Hence, the following table 2 show level of internal auditing role in public sector.

Table 2 The role of internal audit unit in effective utilization of public resource

\begin{tabular}{|l|l|l|l|l|}
\hline Level of internal audit role & Frequency & $\%$ & Valid \% & Cumulative \%t \\
\hline low & 5 & 8.3 & 8.3 & 8.3 \\
\hline Medium & 16 & 26.7 & 26.7 & 35.0 \\
\hline High & 39 & 65.0 & 65.0 & 100.0 \\
\hline Total & 60 & 100.0 & 100.0 &
\end{tabular}

Source: questionnaire (2019)

When it comes to the role of internal audit in effective utilization of public resource, the respondents are asked to rate the above roles in safeguarding public resources in SNNPRS sectorial bureaus on three point scale (low, medium and high) role in protecting public resources. Accordingly, about $39(65.0 \%)$ of respondents agreed that internal audit unit that was established in sectorial bureaus has high and significant role in safeguarding public resources followed by $16(26.7 \%)$ medium and $5(8.3 \%)$ low. This implies that internal auditing in public sector plays a significant role safeguarding and effective utilizations by creating deterrence on fault makers and make them responsible and accountable for any public resources used improperly.

\subsection{Challenges internal audit practice in public resources in of bureaus in SNNPRS}

Finally, the researcher has asked the respondents about the challenges that face internal unit in bureaus. The respondents responded that factors that negatively affecting the internal auditors in carrying out internal audit activity in public sector bureaus of SNNPRS are lack of expertise, leading to trivial audit findings and lack of management respect, lack of opportunity for professional development, domination by dishonest management and staff members, leading to the neglect of sensitive areas where controls are weak and encourage abuses, repetitive audit routines which staff members can predict, inability to insist on getting significant information because of fears of losing promotion opportunities and job security, top managers who are engaged in avoiding controls to the detriment of the entity, management and employees do not maintain and demonstrate a positive and supportive attitude toward internal controls, and wrong perception of the audit function and auditors by staff of the public body.

\section{Conclusion, recommendation and direction for the further research}

\subsection{Conclusions:}

Conclusion is the process of making generalization based on findings of sample to total population. Therefore, the findings revealed from this study were generalized to all bureaus in SNNPRS. Even if the internal audit function in public bureaus of SNPRS plays significant role in effective and efficient use of public resources, it is negatively challenged by factors such as lack of know-how, lack of management support, restricted access to necessary audit evidence, lack of opportunity for professional development, lack of information technology facilities and negative attitude towards internal controls and audit function.

\subsection{Recommendation;}

Based on findings of the study, it is recommended that SNNPR sectorial bureaus has to work on the following issues in order to increase the role of internal audit unit in safeguarding the public resources in one hand and to enhance the skill of internal auditors other hand to reduce challenges faced by internal audit unit .In order to enhance the role of internal audit in safeguarding public resources, the internal auditors should possess the knowledge and skill required it effectively conduct internal audit activity. Besides, the researcher recommended that the bureaus in SNNPRS should hire qualified internal auditors and let the existing internal auditors get the qualification by establishing a mechanism for human resources development and training of staff in accredited 
institutions at local area and in a foreign country. Finally, the internal audit unit should have unrestricted rights of access to all personnel, records (both electronic or otherwise) and assets, and be able to obtain such information and explanations as the head of internal audit considers necessary for the proper fulfillment of its responsibilities. Because, the respondents stated that there is restriction in access to sufficient and relevant evidence required before conducting audit work. The inability to getting significant information because of fears of losing promotion opportunities and job security is one key problems that negatively affect the role of internal audit in safeguarding public resources.

\subsection{Direction for the future research}

No any study can be free from limitations. Accordingly, this study has focused only on assessing the role of internal audit in safeguarding public resources of bureaus in SNNPR. Consequently, the findings of this study may be difficult to generalize about all bureaus in all regions and at national. Hence, this study will be improved if it will be done, at other regions and national level by comparing the role of internal audit in protecting the public sector by increasing sampling different sectorial bureaus. Further researchers can also compare the role of internal audit unit in safeguarding both private and public institutions at regional, national and international level. Another possible research can be done on the same topic by employing the econometric model by scientifically discuss the role of internal audit in safeguarding public resources.

\section{Acknowledgements}

First of all, we would like to give unlimited thanks for God for helping us. Next to God, we appreciate Pharma College Hawassa Campus, which is the top private higher education institutions in Ethiopia that striving to serve the community by providing trainings in both undergraduate and postgraduate programs in health science and business fields and supporting problem solving researches systematically. Pharma college is well known in Ethiopia by providing quality education for society and awarded the reward from the hand of Prime minster of Ethiopia, Dr. Abiy Ahemed for being one of the top institutions voluntarily pay their tax obligation in 2018/2019.

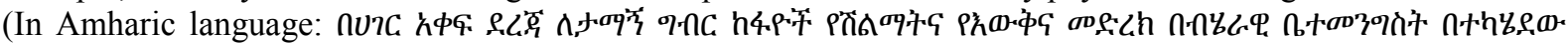

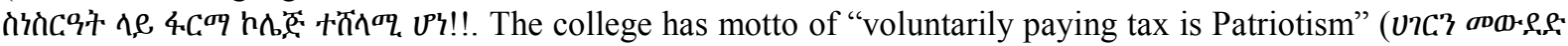

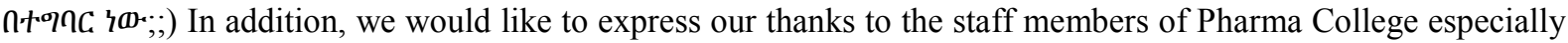
Ato Seyoum Kebede (President of the college), Dr. Wengelawit Seyoum (Vice president of the college), Ato Teklu W/Mariam (Academic dean), Anteneh Fikru (community service and research director), Ato Degent Bunaro (Department head of accounting \& Finance) and Ato Gebyehu Ayele (the campus coordinator) for supporting us in preparing this article. Besides, we also would like to extend our heartfelt thanks to the editors and the anonymous reviewers for their guidance and constructive comments in developing this article.

\section{References}

Amina Ahmed Mohammed. (2016). the Role of Internal Auditors in Private and Public Organizations of Jimma Zone Selected Woredas, Ethiopia. International Journal of Scientific and Research Publications, 6 (11). PP $152-168$

Belay, Z. (2007), Effective Implementation of Internal Audit Function to Promote Good Governance in Public Sector, Ethiopian Civil Service College Research, Publication Consultancy Coordination Office, conference paper, Addis Ababa.

Cohen A. \&Sayag, G. (2010), "the Effectiveness of Internal Auditing: An Empirical Examination of its Determinants in Israeli Organizations": Australian Accounting Review, 20(3), 296-307.

Dawuda. (2010). The Effectiveness of the Internal Audit Units in the Public Sector in Promoting Good Corporate Governance: The Case of the Metropolitan, Municipal and District Assemblies in the Northern Region of Ghana.

Enofe,Dr C. J. Mgbame, V. E. Osa-Erhabor,A. J. Ehiorobo (2013). The Role of Internal Audit in Effective Management in Public Sector. Research Journal of Finance and Accounting www.iiste.org ISSN 2222-1697 (Paper) ISSN 2222-2847 (Online)Vol.5, No.23, 2014

Hawa Aliyi (2016). Factors that Identify the Effectiveness of Internal Audit in Oromia Special. Zone Surrounding Finfinne Administration Finance and Economic Development Offices, Ethiopia. A Research Project paper Submitted to the Department of Accounting and Finance College of Business and Economics Presented in Partial Fulfillment of the Requirements for the Degree of Master of Science in Accounting and Auditing Addis Ababa University Ethiopia

Kirima N. (2016). Factors Affecting the Performance of the Internal Audit Function In Government Ministries in Kenya: A Research Project Submitted to the Chandaria School of Business in Partial Fulfillment of the Requirement for the Degree of Masters in Business Administration (MBA) United States International University - Africa

Mihiret,D.G \& Yismew,AW(2007), “ Internal Audit effectiveness an Ethiopian public sector case study” : 
Managerial Auditing Journal,22(5),470-484.

Morteza Ziaee. (2014).the effect of audit quality on the performance of listed companies Tehran Stock Exchange: International Letters of Social and Humanistic Sciences Online: 2014-02-08 ISSN: 2300-2697, Vol. 21, pp 36-43 doi:10.18052/ www.scipress.com/ ILSHS.21.36 (C) 2014 SciPress Ltd., Switzerland

Ministry of Finance \& Economic Development (2004).Internal Audit Training Manual, Addis Ababa, Ethiopia.

Shewamene Hailemariam. (2014). Determinants Of Internal Audit Effectiveness In The Public Sector, Case Study In Selected Ethiopian Public Sector Offices A Research Paper Submitted To The Post Graduate Office In Partial Fulfillment Of The Requirement For The Master's Degree Of Science In Accounting And Finance (MSc.)

Samuel Mulugeta (2008). Internal Audit: Reporting Relationship in Ethiopian Public Enterprises, a thesis submitted to Addis Ababa University

Tesema Geda (2018). The Role of Internal Audit Practice to Promote Good Governance in Public Institution of Ethiopia: The Case of Jimma Zone. Global Journal of Management and Business Research: D Accounting and Auditing 18 (2) pp 41-55.

Taiwo Olufemi Asaolu1, Samuel Adebayo Adedokun1 and, James UnamMonday (2016). Promoting Good Governance through Internal Audit Function (IAF): The Nigerian Experience. International Business Research; 9 (5) pp. 196 up to 204. Published by Canadian Center of Science and Education

Tesema Geda. (2018).The Role of Internal Audit Practice to Promote Good Governance in Public Institution of Ethiopia: The Case of Jimma Zone. Global Journal of Management and Business Research: D Accounting and Auditing Volume 18 Issue 2 Version 1.0 pp. $41-55$

Taro Yamane (1967). Introduction to statistics. $2^{\text {nd }}$ Edition

Vani (2010 Internal Audit in the Public Sector: Underdeveloped and Underused. Available onlineat.https://blogpfm.imf.org/pfmblog/2010/08/posted-by-sanjay-vani---of-107 countries-in-which-public-expenditure-andfinancial-accountability-pefa-assessments-have-bee.html 